\title{
Structural Characterization of Unfolded States of Apomyoglobin using Residual Dipolar Couplings
}

\author{
Ronaldo Mohana-Borges, Natalie K. Goto, Gerard J. A. Kroon \\ H. Jane Dyson and Peter E. Wright ${ }^{\star}$
}

Department of Molecular Biology and Skaggs Institute of Chemical Biology, The Scripps

Research Institute, 10550

North Pines Road, La Jolla, CA 92037, USA
The conformational propensities of unfolded states of apomyoglobin have been investigated by measurement of residual dipolar couplings between ${ }^{15} \mathrm{~N}$ and ${ }^{1} \mathrm{H}$ in backbone amide groups. Weak alignment of apomyoglobin in acid and urea-unfolded states was induced with both stretched and compressed polyacrylamide gels. In $8 \mathrm{M}$ urea solution at $\mathrm{pH} \mathrm{2.3,} \mathrm{con-}$ ditions under which apomyoglobin contains no detectable secondary or tertiary structure, significant residual dipolar couplings of uniform sign were observed for all residues. At pH 2.3 in the absence of urea, a change in the magnitude and/or sign of the residual dipolar couplings occurs in local regions of the polypeptide where there is a high propensity for helical secondary structure. These results are interpreted on the basis of the statistical properties of the unfolded polypeptide chain, viewed as a polymer of statistical segments. For a folded protein, the magnitude and sign of the residual dipolar couplings depend on the orientation of each bond vector relative to the alignment tensor of the entire molecule, which reorients as a single entity. For unfolded proteins, there is no global alignment tensor; instead, residual dipolar couplings are attributed to alignment of the statistical segments or of transient elements of secondary structure. For apomyoglobin in $8 \mathrm{M}$ urea, the backbone is highly extended, with $\phi$ and $\psi$ dihedral angles favoring the $\beta$ or $\mathrm{P}_{\mathrm{II}}$ regions. Each statistical segment has a highly anisotropic shape, with the $\mathrm{N}-\mathrm{H}$ bond vectors approximately perpendicular to the long axis, and becomes weakly aligned in the anisotropic environment of the strained acrylamide gels. Local regions of enhanced flexibility or chain compaction are characterized by a decrease in the magnitude of the residual dipolar couplings. The formation of a small population of helical structure in the aciddenatured state of apomyoglobin leads to a change in sign of the residual dipolar couplings in local regions of the polypeptide; the population of helix estimated from the residual dipolar couplings is in excellent agreement with that determined from chemical shifts. The alignment model described here for apomyoglobin can also explain the pattern of residual dipolar couplings reported previously for denatured states of staphylococcal nuclease and other proteins. In conjunction with other NMR experiments, residual dipolar couplings can provide valuable insights into the dynamic conformational propensities of unfolded and partly folded states of proteins and thereby help to chart the upper reaches of the folding landscape.

(C) 2004 Elsevier Ltd. All rights reserved.

Keywords: apomyoglobin; unfolded protein; NMR; residual dipolar coupling; conformational ensemble
Abbreviations used: apoMb, apomyoglobin; $\mathrm{NMR}$ nuclear magnetic resonance; NOE, nuclear Overhauser effect; HSQC, heteronuclear single quantum coherence; IPAP, in-phase-antiphase spectra; RDC, residual dipolar coupling.

E-mail address of the corresponding author: wright@scripps.edu

\section{Introduction}

Although major advances have been made in elucidating the folding mechanism of several proteins, detailed understanding of the molecular events that occur during the folding process 
remains limited. It is currently thought that protein folding occurs by a hierarchical process that involves progressive collapse of the polypeptide in a rough, funnel-like energy landscape. ${ }^{1,2}$ Much remains to be learned about the nature of the partly folded states that accompany chain compaction during the folding process. Many proteins are intrinsically unstructured in their biologically functional states; ${ }^{3-6}$ the intrinsic conformational propensities of such proteins have direct relevance to their biological function. Also, the various amyloid diseases involve the formation of pathogenic aggregates from partly folded or misfolded polypeptides. ${ }^{7}$ Structural characterization of unfolded and partly folded proteins is therefore of central importance for understanding the mechanisms of protein folding and the role of unstructured states in normal biological processes and in disease. Due to their high flexibility and disordered nature, such states are unsuitable for structural characterization by X-ray crystallography, but can be studied by nuclear magnetic resonance (NMR) spectroscopy, which can provide detailed structural and dynamic information at the level of individual residues. $^{8}$

Apomyoglobin (apoMb) has been considered a paradigm in protein folding because it forms a number of partly folded states of varying compactness and secondary structure content that can be studied at equilibrium, providing insights into its folding landscape. ${ }^{9-12}$ The protein folds by way of an on-pathway kinetic intermediate, which has extensive helical structure. ${ }^{13-16}$ The heme-containing holoprotein adopts a compact structure containing eight $\alpha$-helices (designated $\mathrm{A}$ to $\mathrm{H}$ ); although the apoprotein is less stable, it retains an extensive hydrophobic core and most of the secondary structure, as well as specific tertiary interactions within the hydrophobic clusters. ${ }^{17,18}$ Acid denaturation of apoMb occurs in two distinct stages, ${ }^{19,20}$ forming a compact molten globule at $\mathrm{pH} 4.1$ with a helix content of $\sim 35 \%$, and then a more highly denatured state at $\mathrm{pH} 2.3$ with a smaller content of helix. The transient helical secondary structure formed in the $\mathrm{pH} 2.3$ state $^{10}$ is disrupted in the presence of $8 \mathrm{M}$ urea. ${ }^{12}$

While chemical shifts, and short and mediumrange NOEs provide valuable insights into the secondary structural propensities of the polypeptide backbone in unfolded and partly folded proteins, ${ }^{21}$ it has generally proved difficult to observe long-range NOEs for unfolded or partly folded states. To circumvent this problem, several groups have utilized site-specific nitroxide spin labeling to probe transient long-range interactions in disordered proteins. $^{22-25}$ An alternative approach that has recently been introduced involves the measurement of residual dipolar couplings (RDC) in unfolded proteins that are weakly oriented in strained polyacrylamide gels. ${ }^{26}$ Dipolar couplings contain information on the orientation of internuclear vectors and have become an important adjunct to traditional struc- tural constraints in refinement of NMR structures of globular proteins. ${ }^{27,28}$ RDCs are measured by weakly aligning a macromolecule in slightly anisotropic nematic liquid crystalline media, such as detergent bicelles or filamentous phages, or in anisotropically compressed gels that interfere with the isotropic tumbling of the macromolecule in the solution. ${ }^{29-32}$ The small degree of alignment resulting from the anisotropic environment leads to incomplete averaging of the dipolar coupling between magnetic nuclei close in space. The magnitude of the RDC is dependent on the orientation of an internuclear vector relative to the alignment tensor of the protein as a whole. In other words, bond vectors such as ${ }^{15} \mathrm{~N}-{ }^{1} \mathrm{H}$ or ${ }^{13} \mathrm{C}-{ }^{1} \mathrm{H}$ can be oriented relative to a global alignment tensor fixed in the molecular frame, regardless of their location in the molecule. ${ }^{29}$ Alternatively, the information can be interpreted in terms of angular relations between pairs of bond vectors that are independent of the intervening distance. The magnitude of the dipolar coupling $D_{\mathrm{NH}}$ between ${ }^{15} \mathrm{~N}$ and its covalently bound ${ }^{1} \mathrm{H}$ is given by equation (1):

$$
\begin{aligned}
D_{\mathrm{NH}}= & -S \gamma_{\mathrm{N}} \gamma_{\mathrm{H}} / \mathrm{r}_{\mathrm{NH}}^{3}\left[A_{\mathrm{a}}\left(3 \cos ^{2} \theta-1\right)\right. \\
& \left.+3 / 2 A_{\mathrm{r}}\left(\sin ^{2} \theta \cos 2 \phi\right)\right]
\end{aligned}
$$

where $S$ is the generalized order parameter describing internal motions of the $\mathrm{N}-\mathrm{H}$ bond vector, $\gamma_{\mathrm{N}}$ and $\gamma_{\mathrm{H}}$ are the gyromagnetic ratios of ${ }^{15} \mathrm{~N}$ and ${ }^{1} \mathrm{H}, A_{\mathrm{a}}$ and $A_{\mathrm{r}}$ are the axial and rhombic components of the alignment tensor, and $\theta$ and $\phi$ are the angles relating the orientation of the $\mathrm{N}-\mathrm{H}$ bond vector to the alignment tensor.

Experimentally, the limited $\mathrm{pH}$ range, temperature range, and solution conditions over which bicelles and phages form nematic liquid crystals make them of limited applicability for studies of denatured proteins. In contrast, strained aligned polyacrylamide gels are a useful alternative alignment medium because they are stable and inert over a broad range of conditions. Recently, nonzero RDCs were observed for the denatured state of truncated staphylococcal nuclease $(\Delta 131 \Delta)$ and for short unstructured peptides weakly aligned in polyacrylamide gels. ${ }^{26,33-35}$ The observation of measurable RDC in highly flexible polypeptides is counterintuitive because internal motions and conformational averaging might be expected to result in vanishingly small residual dipolar couplings. In the case of denatured staphylococcal nuclease, the RDCs were interpreted in terms of persistent native-like topology and structure, even in $8 \mathrm{M}$ urea. ${ }^{26,33,34}$

Here, we report the measurement of RDCs in unfolded states of apoMb at $\mathrm{pH} 2.3$ and in $8 \mathrm{M}$ urea at $\mathrm{pH}$ 2.3. The local and long-range conformational propensities and dynamics of these states have been characterized in detail using NMR methods. ${ }^{9,10,12,25}$ We show that the RDC data for these unfolded states of apomyoglobin can be interpreted on the basis of local conformational 


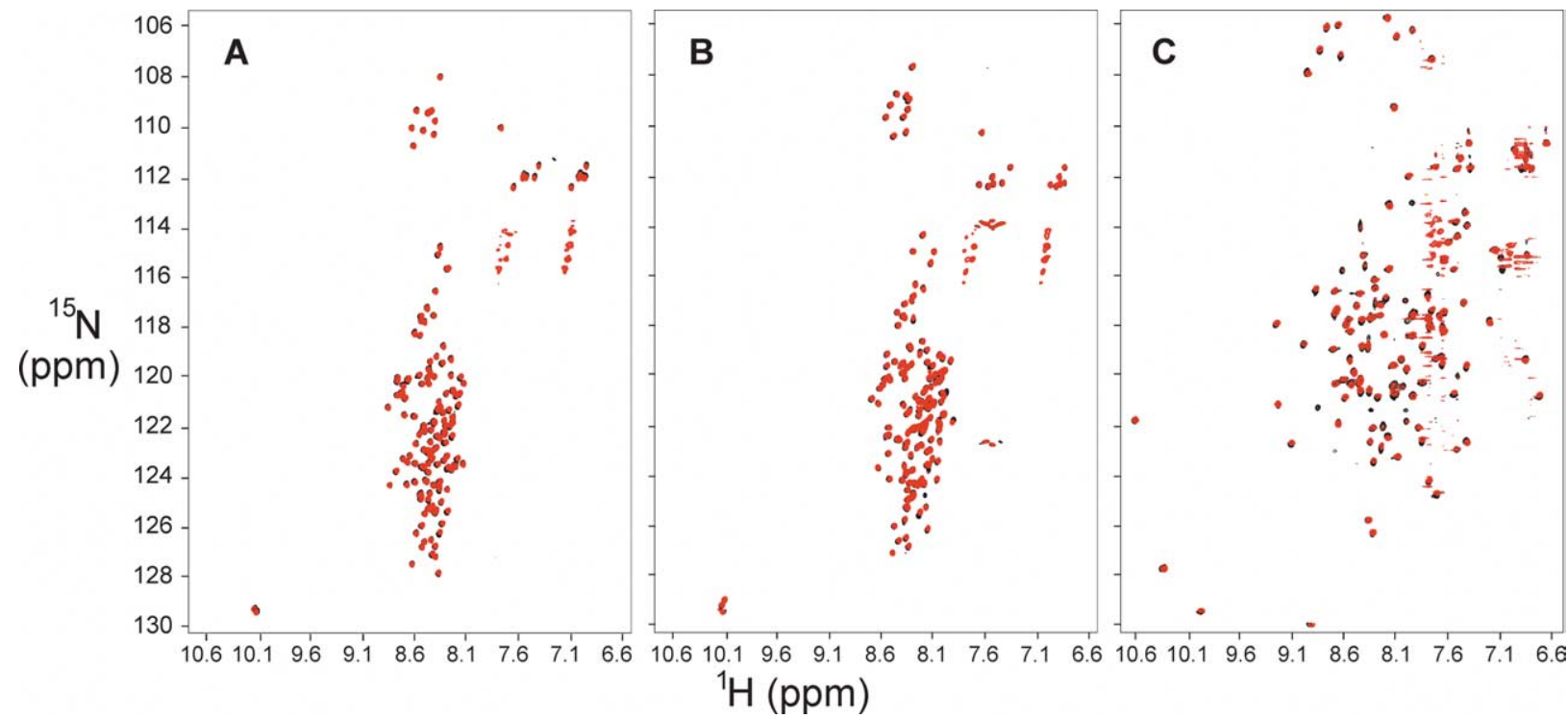

Figure 1. Superposition of ${ }^{1} \mathrm{H}-{ }^{15} \mathrm{~N}$ HSQC spectra of apoMb samples in solution (black cross-peaks) and cast into $10 \%$ polyacrylamide gel (red cross-peaks). A, Urea-denatured state, in $8 \mathrm{M}$ urea at $\mathrm{pH}$ 2.3; B, acid-unfolded state, $\mathrm{pH} 2.3$; $\mathrm{C}$, native state, $\mathrm{pH}$ 6.1. The band of peaks near 7.0 and $7.7 \mathrm{ppm}$ arises from the amide groups of the polyacrylamide gel. ${ }^{31}$

propensities and the well-known physicochemical properties of flexible polypeptide chains, rather than models that invoke the persistence of nativelike structure under denaturing conditions. We also discuss the potential role of residual dipolar couplings for mapping the conformational ensemble of unfolded states of proteins.

\section{Results and Discussion}

\section{Polyacrylamide gels as weak alignment media for unfolded proteins}

Neither bicelles nor filamentous bacteriophages are suitable for measurement of residual dipolar couplings for apomyoglobin, even under native conditions. The protein resonances are broadened beyond detection in the presence of these media, indicating significant interactions between apomyoglobin and the alignment medium itself. However, by using strained polyacrylamide gels $^{31,32}$ it was possible to obtain high-resolution ${ }^{1} \mathrm{H}-{ }^{15} \mathrm{~N}$ heteronuclear single quantum coherence (HSQC) spectra of apomyoglobin in several unfolded or partly folded states. Figure 1 shows ${ }^{1} \mathrm{H}_{-}{ }^{15} \mathrm{~N}$ HSQC spectra of apoMb in $8 \mathrm{M}$ urea at $\mathrm{pH}$ 2.3, acid-unfolded ( $\mathrm{pH} 2.3)$, and native ( $\mathrm{pH}$ 6.1) states, both in isotropic solution (black) and in $10 \%(\mathrm{w} / \mathrm{v})$ polyacrylamide gels (red). Clearly, there are no significant changes in any of the spectra when the protein solutions are cast into the gel. Since ${ }^{1} \mathrm{H}-{ }^{15} \mathrm{~N}$ cross-peaks are very sensitive to even slight changes in their chemical microenvironment, these observations strongly suggest that the conformational ensembles of apoMb in the various unfolded states are not perturbed significantly by the presence of the gel matrix.
Furthermore, ${ }^{15} \mathrm{~N} R_{2}$ relaxation rates measured for the highly denatured state in $8 \mathrm{M}$ urea at $\mathrm{pH} 2.3$ are very similar in isotropic solution and in the polyacrylamide gel (data not shown).

\section{$D_{\mathrm{NH}}$ of unfolded states of apoMb}

Experimentally, dipolar couplings can be extracted from 2D in-phase-antiphase (IPAP)HSQC spectra recorded under both anisotropic and isotropic conditions. ${ }^{36} \mathrm{~A}$ representative region of the IPAP-HSQC spectrum of apomyoglobin in $8 \mathrm{M}$ urea at $\mathrm{pH} 2.3$ is shown in Figure 2. For

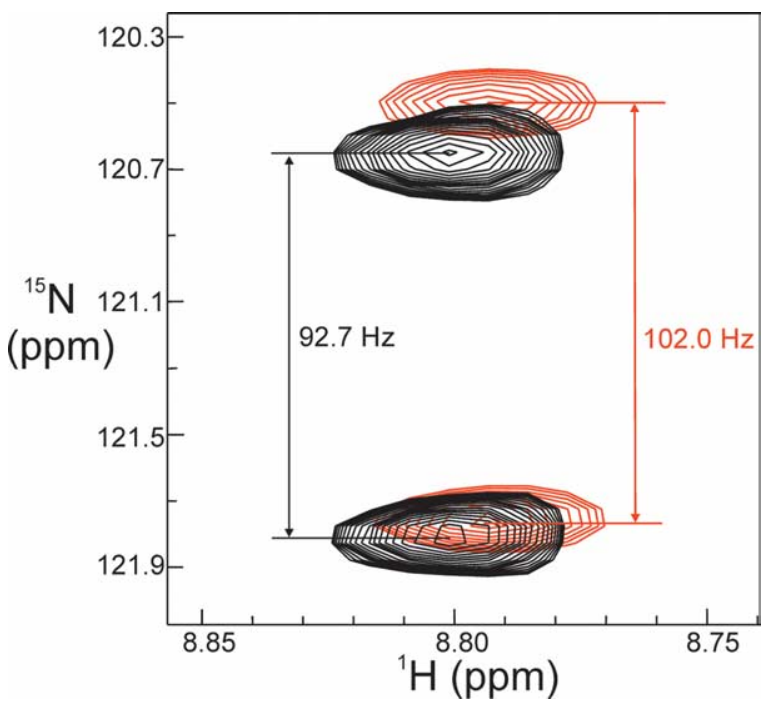

Figure 2. Region of the 2D IPAP-HSQC spectrum of apomyoglobin in $8 \mathrm{M}$ urea at $\mathrm{pH} 2.3$, showing the ${ }^{15} \mathrm{~N}-{ }^{1} \mathrm{H}$ coupling for His82 in isotropic solution (black) and in a stretched polyacrylamide gel (red). 
unfolded states of apomyoglobin, however, the ${ }^{1} \mathrm{H}$ chemical shift dispersion is very poor, resulting in overlap of many cross-peaks in the HSQC spectrum; we therefore used the 3D HNCO-IPAP experiment ${ }^{37}$ to separate the ${ }^{15} \mathrm{~N}-{ }^{1} \mathrm{H}$ cross-peaks in a third dimension according to differences in ${ }^{13} \mathrm{CO}$ chemical shifts. There are two ways in which polyacrylamide gels can be strained to create anisotropic environments. A compressed gel can be formed by subjecting a cylindrical gel with a diameter smaller than the internal diameter of the NMR tube to axial compression. ${ }^{31,32}$ Alternatively, a gel can be stretched in the axial direction (compressed radially) by casting it in a cylindrical tube that is wider than the NMR tube, then squeezing it into a bottomless NMR tube. ${ }^{38}$ These two types of strained gels differ in the orientation of the molecular alignment tensor of the solute molecules with respect to the applied magnetic field. In the stretched gel, the long axis of the protein solute aligns parallel with the magnetic field, whereas the alignment axis is orthogonal to the field for a compressed gel. This approximately doubles the magnitude of the dipolar couplings relative to those obtained in a stretched gel of identical density and degree of compression (i.e. the same aspect ratio) and leads to a reversal in sign. ${ }^{31,38}$ This is illustrated in Figures 3 and 4, which show the residual dipolar couplings measured in compressed gels and stretched gels for apoMb in $8 \mathrm{M}$ urea, $\mathrm{pH} 2.3$ and at $\mathrm{pH} 2.3$ without urea.

For urea-denatured apoMb in the compressed gel, the $D_{\mathrm{NH}}$ value is positive for all residues for which data could be obtained (Figure 3A), while in the stretched gel, larger values of opposite sign are observed (Figure 3B). The $D_{\mathrm{NH}}$ values for most resonances of acid-unfolded apoMb at $\mathrm{pH} 2.3$ also show the expected change in sign between the compressed and stretched gels (Figure 4). However, in contrast to the urea-denatured state, the residual dipolar couplings are not uniformly of the same sign. The $D_{\mathrm{NH}}$ values for each residue in the compressed and stretched gels are highly correlated (Figures 3C and 4C). The negative slope of the correlation plots reflects the expected reversal of the sign of $D_{\mathrm{NH}}$ between stretched and compressed gels. The observed correlations confirm that even these highly flexible unfolded states undergo partial alignment within the pores of the strained polyacrylamide gel.

According to equation (1), the magnitude of the residual dipolar coupling observed should be proportional to $S$, the generalized order parameter, and $\left(3 \cos ^{2} \theta-1\right)$, which describes the orientation of the internuclear vector with respect to the applied magnetic field. Given the intrinsic flexibility and high degree of disorder of the ureadenatured and acid-denatured states of apomyoglobin, it is at first surprising that RDCs can be observed at all. Intuitively, one would expect the magnitude of the RDC in an unfolded state to be reduced to zero by averaging of $\left(3 \cos ^{2} \theta-1\right)$ over all possible orientations of the internuclear vector
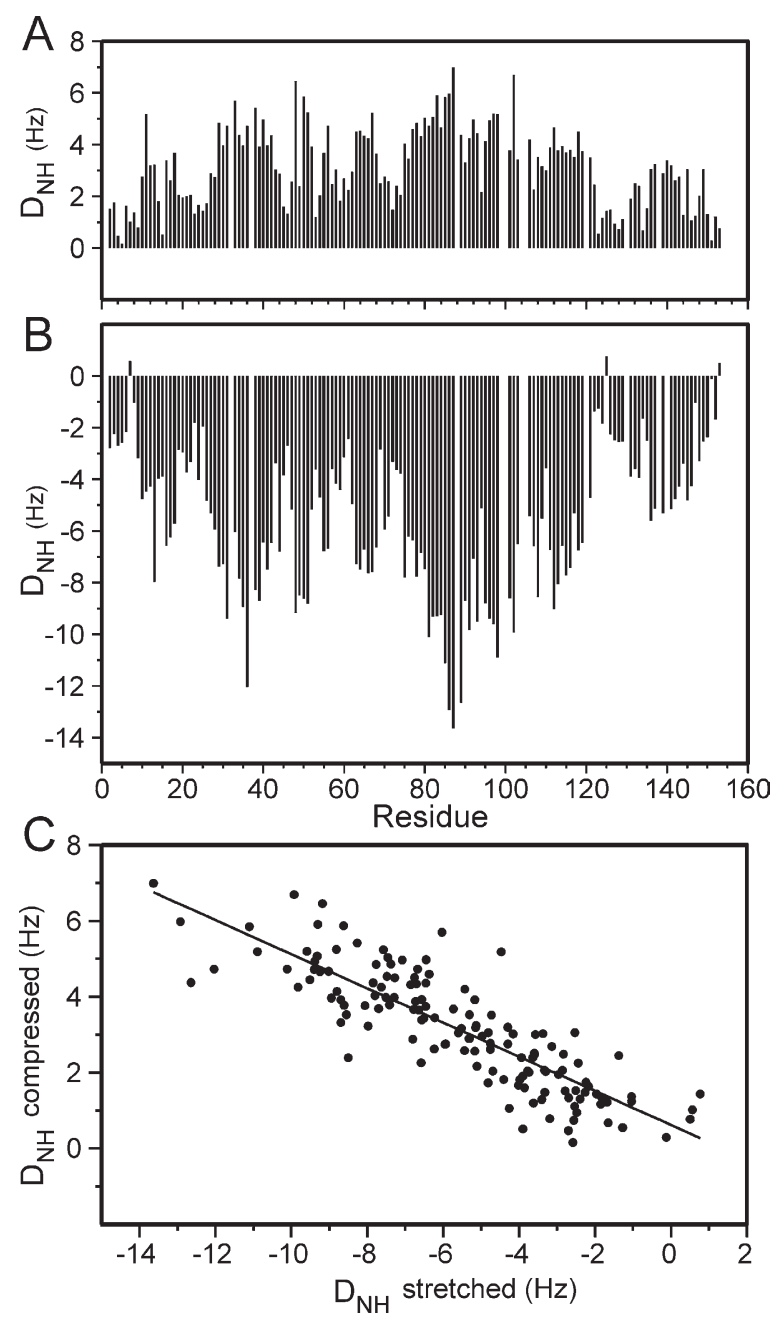

Figure 3. ${ }^{15} \mathrm{~N}-{ }^{1} \mathrm{H}$ residual dipolar couplings as a function of residue number for apomyoglobin in $8 \mathrm{M}$ urea $(\mathrm{pH}$ 2.3). A, Compressed polyacrylamide gel; B, stretched polyacrylamide gel; $C$, correlation between residual dipolar couplings in stretched and compressed gels. RDCs could be measured for all residues except the four proline residues $(37,88,100,120)$ and six residues $(32,99,104,105,130,138)$ for which the NH resonances were overlapped and could not be resolved. No data were obtained for the $\mathrm{NH}$ of Lys140 in the stretched gel medium.

in the conformational ensemble. However, we clearly observe RDCs of significant magnitude for apomyoglobin in two highly unfolded states.

Non-zero RDCs have previously been observed for denatured states of staphylococcal nuclease and eglin C, and for short peptides. ${ }^{26,33-35,39,40}$ The RDCs for urea-denatured staphylococcal nuclease and eglin $C$ were interpreted as evidence of longrange ordering, with persistence of native-like global topology in the denatured state. ${ }^{26,40}$ For apomyoglobin, there is no correlation between the RDCs measured in denatured states and those for the native folded protein (Figure 5). Our data support a different interpretation, that the non-zero RDCs observed for highly unfolded states of apomyoglobin (and, by extrapolation, for other 


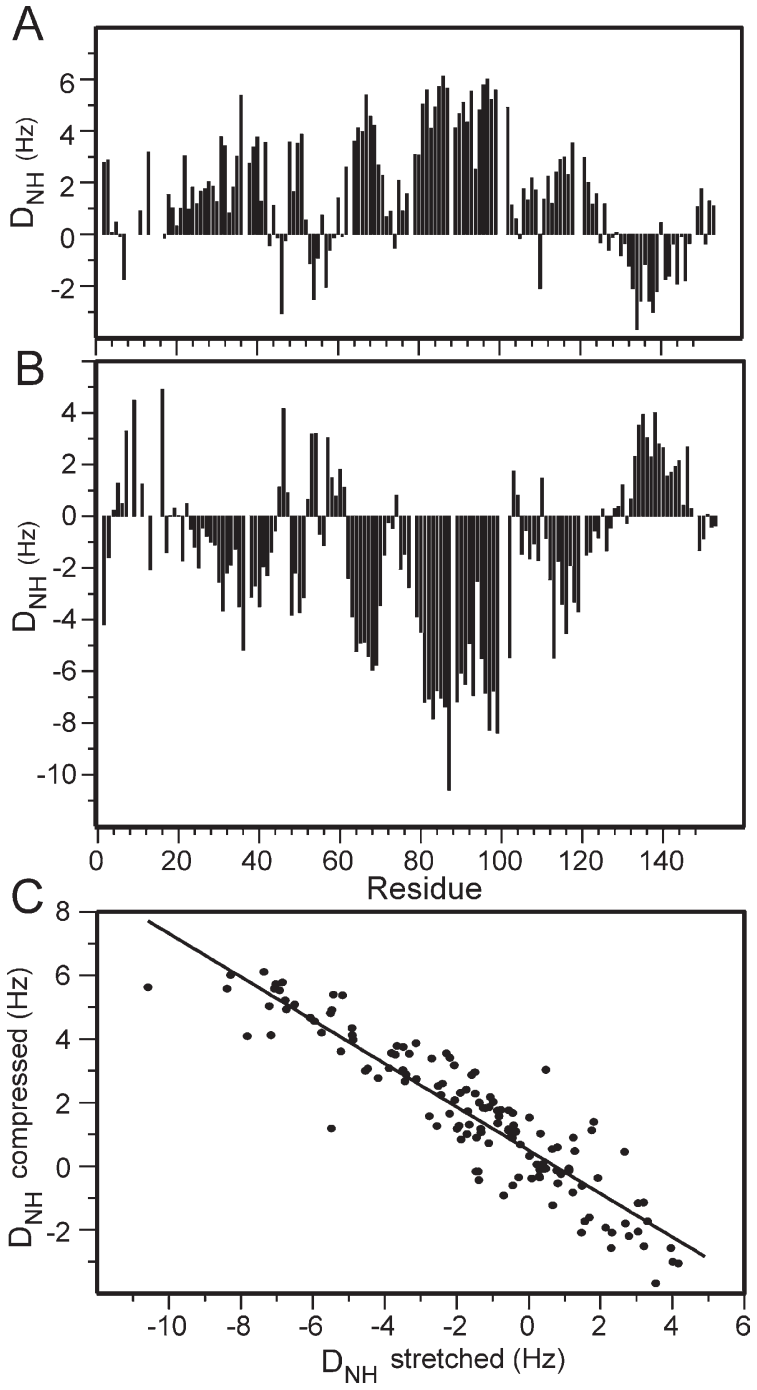

Figure $4 .{ }^{15} \mathrm{~N}-{ }^{1} \mathrm{H}$ residual dipolar couplings as a function of residue number for acid unfolded apomyoglobin at $\mathrm{pH}$ 2.3. A, Compressed polyacrylamide gel; $\mathrm{B}$, stretched polyacrylamide gel; $\mathrm{C}$, correlation between residual dipolar couplings measured in stretched and compressed gels. Due to overlap or broadness of the resonances, no data could be obtained for residues 8,9 , $10,12,14,15,16,63,78,101,119$ and 148 in the compressed gel and 8, 10, 12, 14, 15, 78, 101 and 148 in the stretched gel. proteins) arise from the intrinsic properties of the unfolded polypeptide chain. We base this interpretation on the following logic. Firstly, chemical shifts, ${ }^{15} \mathrm{~N}$ relaxation data, and spin labeling experiments provide incontrovertible evidence that the unfolded state of apoMb in $8 \mathrm{M}$ urea at $\mathrm{pH} 2.3$ is highly flexible and is devoid of longrange order. ${ }^{12,25}$ Secondly, there are no significant changes in the ${ }^{1} \mathrm{H}-{ }^{15} \mathrm{~N}$ HSQC spectra of the protein in the presence or absence of the polyacrylamide gel (Figure 1). The cross-peaks are neither shifted nor broadened and there are no significant changes in ${ }^{15} \mathrm{~N} R_{1}$ or $R_{2}$ relaxation rates, arguing that the gel medium does not change the structure or dynamics of the conformational ensemble in any way. Thus, the conformational propensities and backbone dynamics previously mapped for urea and acid-denatured states of apomyoglobin in free solution $^{10,12}$ should be applicable to the strained polyacrylamide gels. Thirdly, RDCs obtained in the presence and absence of urea (Figures 3 and 4) can be interpreted in a straightforward manner on the basis of the structural propensities and dynamics determined previously for unfolded states of the protein in isotropic solution.

The structure and dynamics of the conformational ensemble formed under these denaturing conditions have been investigated in great detail in our laboratory by analysis of chemical shifts, NOEs, backbone ${ }^{15} \mathrm{~N}$ spin relaxation rates, and the resonance broadening effects of paramagnetic spin labels. ${ }^{9,10,12,25}$ These data show that the polypeptide chain is highly flexible in both the urea and aciddenatured states, with large amplitude backbone fluctuations on picosecond and nanosecond timescales. However, the chain does not behave as a free-flight random coil in either denaturant. In the acid-unfolded protein at $\mathrm{pH} 2.3$, chemical shift measurements indicate a small but significant propensity for helical structure in the regions corresponding to the $\mathrm{A}, \mathrm{D} / \mathrm{E}$ and $\mathrm{H}$ helices in the folded protein, which is abolished by addition of $8 \mathrm{M}$ urea. ${ }^{9,10,12}$ In the urea-unfolded state, deviations of ${ }^{13} \mathrm{C}^{\alpha},{ }^{13} \mathrm{CO}$, and ${ }^{1} \mathrm{H}^{\alpha}$ chemical shifts from random coil values, obtained under identical conditions and corrected for local sequence
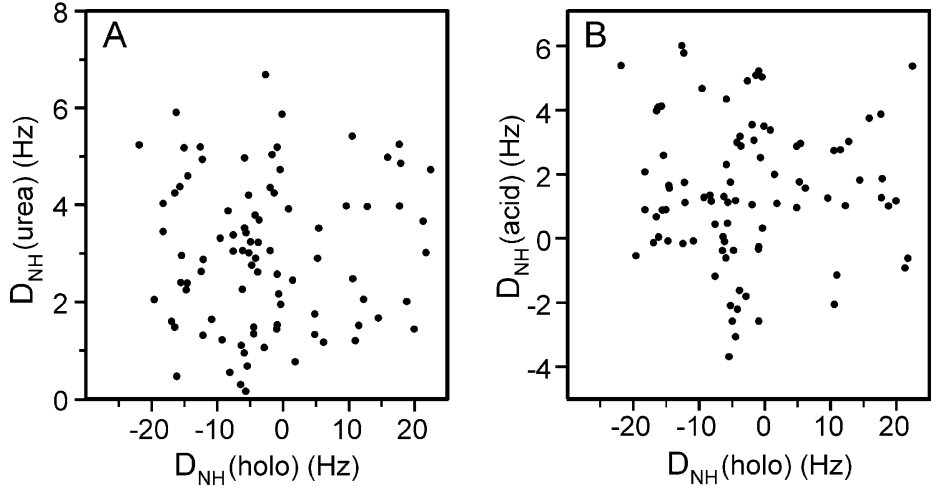

Figure 5. Scatter plots of ${ }^{15} \mathrm{~N}-{ }^{1} \mathrm{H}$ residual dipolar couplings for myoglobin in the native and denatured states. A, Plot of $D_{\mathrm{NH}}$ values for holomyoglobin versus $\mathrm{D}_{\mathrm{NH}}$ of apomyoglobin in $8 \mathrm{M}$ urea at $\mathrm{pH}$ 2.3. B, Plot of $D_{\mathrm{NH}}$ values for holomyoglobin versus $D_{\mathrm{NH}}$ of aciddenatured apomyoglobin at $\mathrm{pH}$ 2.3. The residual dipolar couplings for holomyoglobin at $\mathrm{pH} 5.6$ and $35^{\circ} \mathrm{C}$, were measured in compressed $8 \%$ polyacrylamide gels. The residual dipolar couplings shown for the denatured apoprotein are also for compressed gels. 
effects, ${ }^{41,42}$ reveal that most regions of the polypeptide have a slight preference for extended backbone conformations, i.e. there is a higher probability that backbone dihedral angles fall in the broad minimum encompassing the $\beta$ and polyproline II conformations rather than the $\alpha$-region of $\phi, \psi$ space.

It is striking that all of the RDC values for apomyoglobin in $8 \mathrm{M}$ urea at $\mathrm{pH} 2.3$ have the same sign, that is, in the compressed gel all of the RDCs are positive (Figure 3A), while in the stretched gel nearly all of the $D_{\mathrm{NH}}$ values are negative (Figure 3B). For the acid-unfolded protein, most, but not all, of the $D_{\mathrm{NH}}$ values in the compressed gel are positive (Figure 4A), while in the stretched gel the majority are negative (Figure 4B); the regions of the polypeptide that are "fully unfolded" give rise to RDCs of a particular sign, positive in compressed gels and negative in stretched gels.

\section{RDC in unfolded states reflects local not long- range structure}

A consideration of these results in terms of the properties of polymers rather than those of folded proteins provides an explanation not only of the amplitudes of the RDCs but also of their signs and the changes of sign that occur when a propensity for helix is present. It has been predicted theoretically and demonstrated experimentally that the overall shape of a random-walk polymer is not spherically symmetrical; rather, there is a propensity for the chain to adopt extended structures with highly anisotropic shape. ${ }^{43,44}$ Real polypeptides do not behave as ideal random coils in which the backbone dihedral angles of each amino acid residue are independent of its neighbors; in other words, they do not obey the Flory isolated pair hypothesis. ${ }^{45,46}$ The behavior of denatured proteins in solution is usually described using rotational isomeric state theory, in which the chain is treated as a polymer of jointed statistical segments that are randomly oriented with respect to each other. ${ }^{45,47}$ Due to steric restrictions on rotations about the backbone $\phi$ and $\psi$ dihedral angles, the polypeptide chain exhibits local stiffness, which is dependent upon the amino acid composition (sequence). The behavior of the chain can also be described in terms of its persistence length (approximately half the statistical segment length, for homopolypeptides ${ }^{47}$ ), which is a measure of the length over which the chain persists in the same general direction. The persistence length for denatured polypeptides, determined experimentally from small-angle X-ray scattering and NMR relaxation measurements, ${ }^{48,49}$ is five to seven amino acid residues. Thus, each statistical segment comprises several amino acid residues, with a propensity towards extended conformations, and is highly anisotropic in shape with its own alignment tensor. We propose that residual dipolar couplings in unstructured polypeptides originate from transient alignment of local regions of the chain, i.e. from alignment of the statistical segments. A similar explanation has recently been given by Louhivuori et al., ${ }^{50}$ who described a theoretical model for the residual dipolar couplings based on the local alignment of statistical elements in random flight chains.

In unfolded polypeptides, the backbone fluctuates over an ensemble of conformations with $\phi$ and $\psi$ dihedral angles sampling the $\beta, \alpha_{R}$, and polyproline II $\left(\mathrm{P}_{\mathrm{II}}\right)$ minima on the Ramachandran $\phi, \psi$ energy surface. ${ }^{45,51}$ The experimentally observed residual dipolar coupling will be a population weighted average over all low-energy backbone conformations in the ensemble. The dominant backbone conformation in unstructured peptides in water as well as in chemically denatured proteins is extended, with $\phi, \psi$ angles preferentially populating the $\beta$ or $P_{I I}$ energy wells. ${ }^{51-56}$ The backbone $\mathrm{N}-\mathrm{H}$ vectors of a statistical segment constrained to conformations within the $\beta$ and $P_{I I}$ wells will on average be oriented in a direction that is approximately perpendicular to the chain direction, i.e. perpendicular to the principal axis of the local alignment tensor (Figure 6A and $B)$. Thus, in a stretched gel, the $\mathrm{N}-\mathrm{H}$ vectors

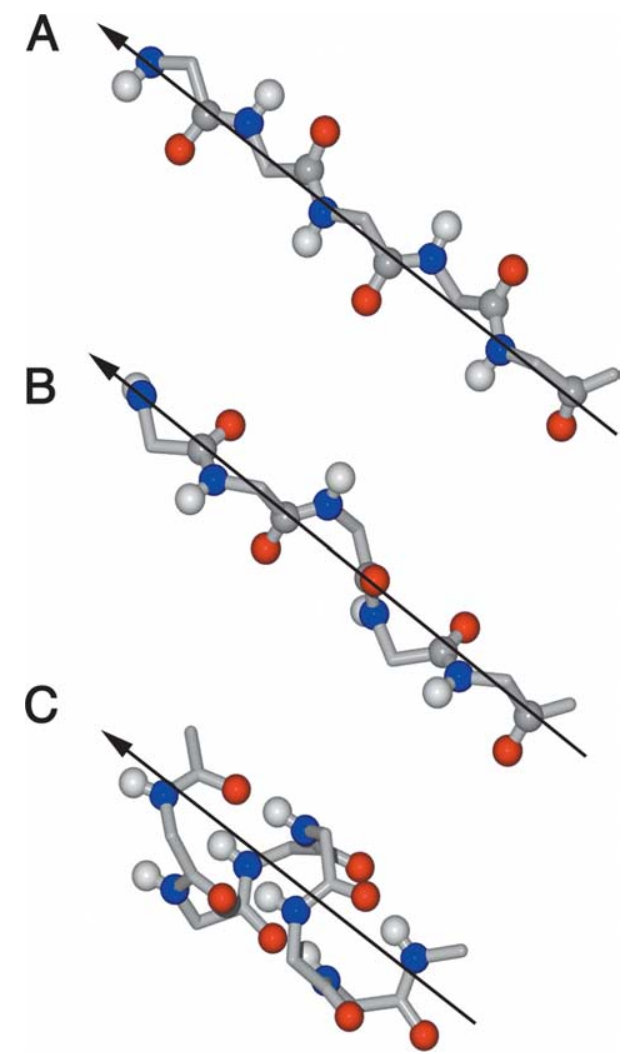

Figure 6. Schematic diagrams showing the backbone conformations of polypeptide statistical segments (five to seven residues) that preferentially populate dihedral angles in the (A) $\beta,(B)$ polyproline II, and (C) $\alpha_{R}$ minima on the $\phi, \psi$ energy surface. The black arrows indicate the direction of the principal axis of the alignment tensor for each statistical segment. 


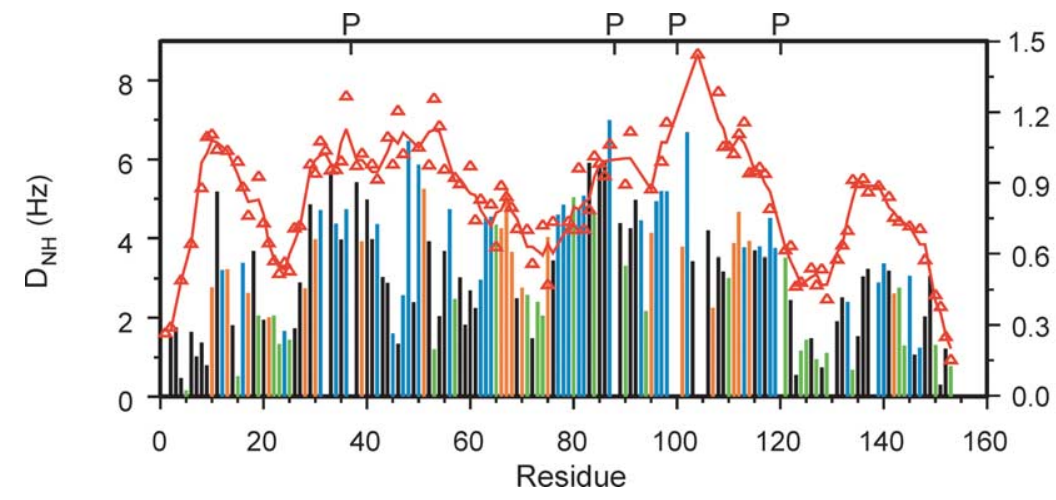

Figure 7. Effect of backbone dynamics and amino acid sequence on residual dipolar couplings for urea-denatured apoMb ( $\mathrm{pH}$ 2.3). The histogram shows $D_{\mathrm{NH}}$ values for a compressed gel plotted as a function of residue number. The location of Gly and Ala residues is indicated by green bars, residues with $\beta$-branched side-chains (Val, Ile, Thr) by orange bars, and charged residues (Arg, Lys, and His only at $\mathrm{pH} 2.3$ ) are highlighted in blue. The location of the proline residues in indicated. Calculated values of the $J(0)$ spectral density ${ }^{12}$ are plotted as red data points (triangles) and a kernel smoothed curve. will be preferentially oriented perpendicular to the applied magnetic field, the average value of $\left(3 \cos ^{2} \theta-1\right)$ will be $\sim-1$ and hence the $D_{\mathrm{NH}}$ value will be negative $\uparrow$. This is precisely what is observed experimentally for urea-denatured apomyoglobin, with almost all residues exhibiting negative $D_{\mathrm{NH}}$ values in the stretched gel (Figure 3B). Conversely, for a compressed gel, all $D_{\mathrm{NH}}$ values are predicted to be positive in sign, as is observed experimentally (Figure 3A).

For an idealized random-flight polypeptide of the length of apomyoglobin, the $D_{\mathrm{NH}}$ values should be similar for all residues, except for those near the ends of the chain where there is increased local flexibility and the distribution of conformations becomes more spherical. ${ }^{50}$ In other words, for an ideal random coil, a plot of $D_{\mathrm{NH}}$ versus residue number should form a flattened bell-shaped curve. Clearly, urea-denatured apomyoglobin deviates from ideality, since despite the fact that all residual dipolar couplings have the same sign, there is considerable variation in the magnitude of $D_{\mathrm{NH}}$ (Figure 3). From our statistical segment model, one might expect a decrease in the magnitude of the residual dipolar coupling in regions of increased flexibility of the polypeptide chain backbone, i.e. in regions of decreased chain stiffness. Figure 7 shows a superposition of the $D_{\mathrm{NH}}$ values on the $J(0)$ spectral densities determined from ${ }^{15} \mathrm{~N}$ relaxation measurements for urea-denatured apomyoglobin. ${ }^{12}$ Three distinct minima in $J(0)$ (at residues 21-25, 60-80 and 121-129) are observed in regions that are rich in Gly and Ala residues, and which function as flexible molecular hinges in the polypeptide chain. These regions correspond closely to segments with reduced $D_{\mathrm{NH}}$ values (Figure 7), showing that a local decrease in chain stiffness leads to more effective averaging of the

$\dagger$ In an unfolded polypeptide, ensemble averaging about the long axis of the statistical segment is expected to result in an axially symmetric alignment tensor.
$\mathrm{N}-\mathrm{H}$ vectors. A scatter plot of $J(0)$ versus $D_{\mathrm{NH}}$ (not shown) has a correlation coefficient $R=0.58$.

Several contiguous segments of the apomyoglobin chain, encompassing residues 28-42, 63-68, 77-89, 95-102, and 111-120, exhibit greater than average RDC values. These segments tend to be rich in $\beta$-branched (valine, isoleucine, and threonine) and charged amino acid residues (lysine, arginine, and histidine at $\mathrm{pH} 2.3$ ); most of them also contain proline (residues 37, 88, 100, 120). Proline and the $\beta$-branched amino acids predispose the backbone towards dihedral angles in the $\beta$ and $P_{I I}$ minima, i.e. tend to bias the conformational ensemble towards more extended backbone conformations that would be expected to align more effectively in the strained polyacrylamide gels. It is at first surprising to find arginine and lysine clusters associated with these regions, since both amino acids have high helical propensities. However, recent evidence suggests that short lysine homopeptides, in common with other peptides with ionizable side-chains, have a high propensity to adopt $\mathrm{P}_{\mathrm{II}}$ conformations ${ }^{52,57}$ that would bias the chain towards extended structures.

In addition to the regions of enhanced backbone flexibility, below-average values of $D_{\mathrm{NH}}$ are observed in some other regions of urea-denatured apomyoglobin, e.g. in the CD loop (residues $43-47)$, and probably reflect a local propensity for chain compaction. ${ }^{15} \mathrm{~N}$ relaxation measurements provide evidence for motional restriction of the backbone in the CD loop region due to local hydrophobic cluster formation, which persists even in $8 \mathrm{M}$ urea. $^{12}$ A strong propensity for structure formation in the CD loop region was also observed in a short synthetic peptide in water solution. ${ }^{58}$ Taken together with these earlier results, the reduced $D_{\mathrm{NH}}$ values strongly support a model in which preferential chain compaction occurs for residues 43-47 (sequence FDRFK) in the ureadenatured state. Increased compaction is also indicated for many residues in the segment between Ala53 and Leu61; while the nature of the interactions that lead to preferential local 
compaction in $8 \mathrm{M}$ urea are unknown, it is of interest that this region folds spontaneously into helical structure in both the acid-denatured protein and in peptide fragments. ${ }^{10}$

\section{Local conformational propensities in acid- denatured apomyoglobin}

The $J(0)$ spectral density for acid-denatured apomyoglobin is relatively uniform in all regions of the polypeptide ${ }^{10}$ and therefore the $D_{\mathrm{NH}}$ value is unlikely to be modulated significantly by local variations in backbone dynamics. Rather, variations in $D_{\mathrm{NH}}$ should primarily reflect differences in the structures that contribute to the conformational ensemble. An exception is parts of the $A$ and $G$ helix regions, where exchange broadening leads to increased values of $J(0)$ and makes accurate measurement of $D_{\mathrm{NH}}$ difficult for several residues in these regions; this is the reason for some of the missing data points in Figures 4 and 8 .

The correlation between the RDCs for aciddenatured apoMb in a stretched gel and the deviations of a weighted average of the ${ }^{13} \mathrm{C}^{\alpha}$ and ${ }^{13} \mathrm{CO}$ chemical shifts from sequence-corrected random coil values is shown in Figure $8 \mathrm{~A}$. $D_{\mathrm{NH}}$ is negative throughout the F helix region (residues 81-98) and the central portion of the E helix (resides 63-69), in accord with the indications from the secondary chemical shifts that the polypeptide backbone in these regions preferentially adopts extended chain conformations. In contrast, positive values of $D_{\mathrm{NH}}$ are observed for contiguous residues in the $A$, $\mathrm{D}-\mathrm{E}$, and $\mathrm{H}$ helix regions, corresponding closely to regions of the protein where secondary chemical shifts indicate $15-20 \%$ population of helical structures in rapid dynamic equilibrium with unfolded states. ${ }^{10}$ The sign change can readily be rationalized utilizing the notion of statistical segments and calculating the effect of a local propensity for helix. For a helical segment, the principal axis of the alignment tensor lies along the axis of the helix and the $\mathrm{N}-\mathrm{H}$ vectors are oriented parallel with the axis (Figure 6C). Therefore, in a stretched gel, the $\mathrm{N}-\mathrm{H}$ bond vectors will tend to align with the applied magnetic field $(\theta=0)$ so that the average value of $\left(3 \cos ^{2} \theta-1\right)$ will be $\sim 2$ and $D_{\mathrm{NH}}$ will be positive, in agreement with experimental observations (Figures $4 \mathrm{~B}$ and 8 ). In accord with our apomyoglobin data, a change in the sign of $D_{\mathrm{NH}}$ in local regions of the polypeptide that exhibit a propensity for helix has recently been observed in the acid-denatured state of ACBP. ${ }^{59}$ Further, inspection of the RDC data for the $\Delta 131 \Delta$ fragment of staphylococcal nuclease in aqueous solution (data from Supplementary Material from Shortle \& Ackerman $^{26}$ ) reveals a sign change in regions

A

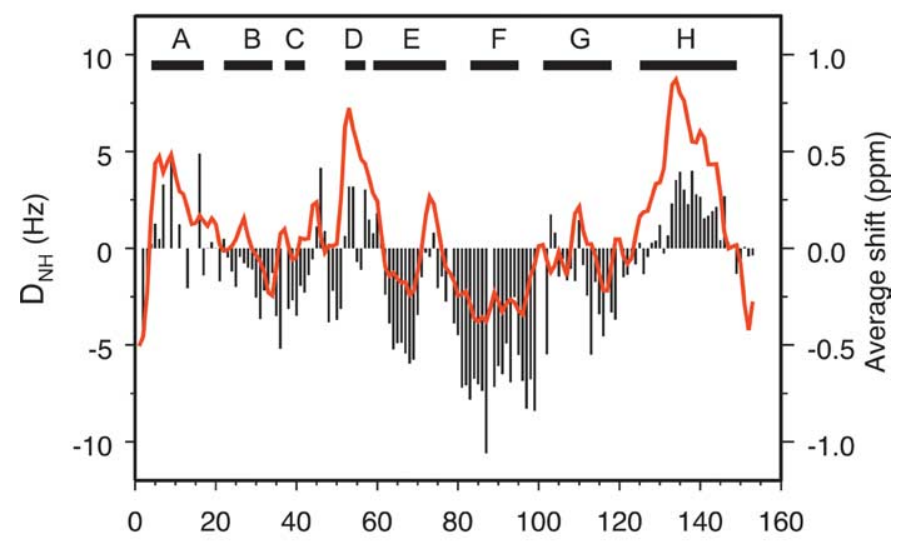

Figure 8. Effect of local conformational propensities on residual dipolar couplings for aciddenatured apoMb ( $\mathrm{pH}$ 2.3). A, Plot of $D_{\mathrm{NH}}$ values for a stretched gel versus residue number (black histogram). Smoothed average deviations of ${ }^{13} \mathrm{C}^{\alpha}$ and ${ }^{13} \mathrm{CO}$ chemical shifts $\left(\Delta_{\text {av }}\left(C^{\alpha} C^{\prime}\right)\right)$ from sequencecorrected random coil values are plotted as a continuous red line. ${ }^{10}$ The average shifts were calculated as $\left(3 \Delta \delta C^{\alpha}+4 \Delta \delta C^{\prime}\right) / 7$, weighted according to the secondary shifts corresponding to fully formed helix, i.e. $2.8 \mathrm{ppm}$ for ${ }^{13} \mathrm{C}^{\alpha}$ and $2.1 \mathrm{ppm}$ for ${ }^{13} \mathrm{C}^{\prime}$ (Yao et al., ${ }^{10}$ Wishart \& Sykes ${ }^{67}$ ). Regions of helical propensity are indicated by positive values of $\Delta_{\text {av }}\left(C^{\alpha} C^{\prime}\right)$ extending over several residues. The black bars indicate the location of the eight helices in the structure of native holomyoglobin. B, Plot of difference in residual dipolar coupling $\left(\Delta D_{\mathrm{NH}}\right)$ between acid-denatured and ureadenatured states, superimposed on $\Delta_{\text {av }}\left(C^{\alpha} C^{\prime}\right)$ (red line). The difference RDC is calculated from the stretched gel data of Figures 3B and $4 \mathrm{~B}$ as $\Delta D_{\mathrm{NH}}=D_{\mathrm{NH}}^{\text {acid }}-D_{\mathrm{NH}}^{\text {urea }}$. 
where chemical shifts and NOE connectivities indicate formation of helical structure. ${ }^{60}$

Additional insights into the nature of the conformational ensemble of the $\mathrm{pH} 2.3$ state can be obtained by calculating the difference in the residual dipolar couplings $\left(\Delta D_{\mathrm{NH}}\right)$ between the urea-denatured and acid-denatured states (Figure 8B). This shows more clearly the decrease in RDC that occurs for much of the polypeptide on going from $8 \mathrm{M}$ urea at $\mathrm{pH} 2.3$ to the aciddenatured form at the same $\mathrm{pH}$. Many of the regions of large positive $\Delta D_{\mathrm{NH}}$ values coincide with regions of the polypeptide where the ${ }^{13} \mathrm{C}^{\alpha}$ and ${ }^{13} \mathrm{CO}$ chemical shifts indicate significant helical propensity (Figure 8B). However, the increase in $\Delta D_{\mathrm{NH}}$ between residues $26-50$ and between residues 103-118 does not appear to be associated with helix formation, but correlates with regions of the polypeptide chain in which relaxation measurements indicate restriction of backbone motions due to local hydrophobic collapse. ${ }^{10}$ These regions encompass much of the B helix, the $C D$ loop, and the $G$ helix of the native folded protein.

The population of helix in the acid-denatured protein can be estimated from the magnitude of the residual dipolar couplings. In the helical segments, the measured $D_{\mathrm{NH}}$ for each residue is a population weighted average between the value for a fully formed helix and the RDC in the unfolded state. To calibrate the change in RDC for the transition from a fully unfolded state to a fully formed helix, we assume that the average RDCs in the $\mathrm{F}$ helix region of the acid-denatured apomyoglobin $\left(\left\langle D_{\mathrm{NH}}^{\text {extended }}\right\rangle=-6.8\right.$ and $+5.0 \mathrm{~Hz}$ for residues 81-98 in the stretched and compressed gels, respectively) represent the limit of $D_{\mathrm{NH}}$ for the unfolded (extended chain) conformation. This represents the expected $D_{\mathrm{NH}}$ value for $\theta=90^{\circ}$, i.e. for $\left(3 \cos ^{2} \theta-1\right)=-1$. For a fully formed helix, the $\mathrm{N}-\mathrm{H}$ vectors will be aligned along the principal axis of the helix $\left(\theta=0^{\circ}\right)$ and $\left(3 \cos ^{2} \theta-1\right)=+2$; therefore, the difference in $D_{\mathrm{NH}}$ value $\left(\Delta D_{\mathrm{NH}}\right)$ corresponding to formation of $100 \%$ population of helix is $3\left|\left\langle D_{\mathrm{NH}}^{\text {extended }}\right\rangle\right|$. The population of helix in the segment between residues $i$ and $j$ is then given by the relationship:

$$
P=\frac{1}{N} \sum_{i}^{j}\left(D_{\mathrm{NH}}^{\mathrm{i}, \text { acid }}-D_{\mathrm{NH}}^{\mathrm{i}, \text { urea }}\right) / 3\left\langle D_{\mathrm{NH}}^{\text {extended }}\right\rangle
$$

where $N$ is the number of residues in the helical segment, and the $D_{\mathrm{NH}}$ for the unfolded state for each residue is taken as that for apomyoglobin in $8 \mathrm{M}$ urea at $\mathrm{pH} 2.3 \dagger$.

Using equation (2), we calculate the following

$\dagger$ Because of differences in aspect ratio of the stretched gels, the RDC for the urea-denatured protein was scaled so that $\left\langle D_{\mathrm{NH}}^{\mathrm{urea}}\right\rangle=\left\langle D_{\mathrm{NH}}^{\text {acid }}\right\rangle$ averaged over the extended chain region, residues 80-98; scaling was unnecessary for data obtained from the compressed gels. helical populations from the RDC data for the stretched (compressed) gels, respectively: A helix region (residues 4-11), 17\% (11\%); D-E helix region (residues 52-61), 22\% (22\%); $\mathrm{H}$ helix region (residues 127-147), 21\% (22\%). These populations are in striking agreement with those calculated from secondary ${ }^{13} \mathrm{C}^{\alpha},{ }^{13} \mathrm{CO}$, and ${ }^{1} \mathrm{H}^{\alpha}$ chemical shifts, namely $15 \%, 22 \%$, and $20 \%$ helical populations for the same segments of the A, D-E, and $\mathrm{H}$ helix regions. ${ }^{10}$ The secondary chemical shifts also suggest a slight propensity to populate local helical structures between residues 72-75 towards the $\mathrm{C}$-terminal end of the $\mathrm{E}$ helix of the folded protein (Figure $8 \mathrm{~B}) ; \Delta D_{\mathrm{NH}}$ is consistent with this interpretation, and the helical population is estimated from the RDCs to be $11 \%$ between residues $70-77$ in the acid-denatured protein. The remarkably good agreement between the populations of helix obtained from chemical shifts and estimated from the residual dipolar couplings provides strong evidence that our model for alignment of unfolded peptide chains is an appropriate one.

\section{Residual dipolar couplings in unfolded proteins}

Residual dipolar couplings for unfolded polypeptides arise through an intrinsically different mechanism than those for folded globular proteins. For folded proteins, $D_{\mathrm{NH}}$ for each amide is determined by the relative orientation of the ${ }^{1} \mathrm{H}_{-}{ }^{15} \mathrm{~N}$ bond vector to the alignment tensor of the entire molecule and $D_{\mathrm{NH}}$ therefore depends upon both the three-dimensional structure of the protein and its overall hydrodynamic shape. In contrast, alignment in unfolded proteins is a property of the polypeptide chain and its constitutive statistical segments, rather than the molecule as a whole. The alignment tensor is determined by the shape anisotropy of the statistical segments, and the measured residual dipolar couplings at individual residues reflect local conformational propensities within the statistical segments. All of the results reported thus far on unfolded proteins, including those on urea-denatured staphylococcal nuclease, eglin C, ACBP, and short peptides, ${ }^{26,33-35,40,59}$ are consistent with this interpretation. For example, the RDCs for the $\Delta 131 \Delta$ fragment of staphylococcal nuclease in $8 \mathrm{M}$ urea all have the same sign (the $D_{\mathrm{NH}}$ values are all positive for a compressed gel, once the published values ${ }^{26}$ are corrected for the negative gyromagnetic ratio of ${ }^{15} \mathrm{~N}$ ), consistent with alignment of statistical segments with $\phi, \psi$ angles preferentially in the $\beta$ and $P_{I I}$ regions. There is no need to invoke the presence of nativelike structure to explain the observed residual dipolar couplings for denatured states of staphylococcal nuclease, apomyoglobin, or any other proteins for which data have been reported. Instead of providing information on the overall structure, as is the case for a folded globular protein, RDC measurements for unfolded states of proteins give very different, but equally useful, information on the composition of the confor- 
mational ensemble. In combination with chemical shift and spin relaxation data, residual dipolar couplings provide important insights into secondary structural propensities and chain compaction in local regions of the unfolded polypeptide chain and therefore hold great promise for mapping the upper reaches of the protein folding landscape.

\section{Methods}

\section{Sample preparation}

Protein labeled uniformly with ${ }^{15} \mathrm{~N}$ or with ${ }^{15} \mathrm{~N} /{ }^{13} \mathrm{C}$ was expressed in Escherichia coli strain BL21-DE3 using a slight modification of published methods. ${ }^{10}$ The inclusion body pellet was solubilized in $0.1 \%(\mathrm{v} / \mathrm{v})$ trifluoroacetic acid and acetonitrile was added to $10 \%$ $(\mathrm{v} / \mathrm{v})$. After HPLC purification in C4-reverse phase column, the protein was lyophilized. For sample preparation, the protein was resuspended in $10 \mathrm{mM}$ sodium acetate $(\mathrm{pH}$ 6.1) and incubated on ice for two hours. The $\mathrm{pH}$ was adjusted back to $\mathrm{pH} 6.1$ to facilitate full protein solubilization. The sample was then spun down for ten minutes at 13,000 $\mathrm{g}$ before buffer exchange on a HiTrap desalting column (Amersham-Pharmacia Biotech) to the final desired $\mathrm{pH}(10 \mathrm{mM}$ sodium acetate and $10 \%{ }^{2} \mathrm{H}_{2} \mathrm{O}$ were present in all $\mathrm{pH}$ values. Approximately $5 \mathrm{mM} \mathrm{HCl}$ was added to obtain $\mathrm{pH} 2.3$ and the buffer containing $8 \mathrm{M}$ urea was prepared according to a published method. ${ }^{12}$ Samples were concentrated (Centriprep 10) to a final concentration of $200 \mu \mathrm{M}$, determined by UV absorbance in $6.0 \mathrm{GdmCl}(20 \mathrm{mM}$ phosphate ( $\mathrm{pH}$ 6.5) $)$ using an extinction coefficient of $\varepsilon_{280}=15,200 \mathrm{M}^{-1} \mathrm{~cm}^{-1}\left(\right.$ Edelhoch $\left.^{61}\right)$.

\section{Polyacrylamide gel preparation and sample casting}

Polyacrylamide gels were prepared according to the protocol described by Sass et al., ${ }^{31}$ from a stock solution containing $29.2 \%(\mathrm{w} / \mathrm{v})$ acrylamide and $0.78 \%(\mathrm{w} / \mathrm{v})$ $N, N^{\prime}$-methylenebisacrylamide. Gels were cast by placing the appropriate volume of acrylamide/bisacrylamide stock solution for the desired gel concentration in a plastic tube immediately following initiation of polymerization by addition of $0.1 \%(\mathrm{w} / \mathrm{v})$ ammonium persulfate and $0.04 \%(\mathrm{v} / \mathrm{v}) \quad N, N, N^{\prime}, N^{\prime}$-tetramethylenediamine (TEMED). The internal diameter (ID) of the tube was $4 \mathrm{~mm}$ for compressed and $5 \mathrm{~mm}$ for stretched gels. After polymerization was complete, the gel was extruded from the tube, cut into lengths of $35 \mathrm{~mm}$ (for compressed gels) and $25 \mathrm{~mm}$ (for stretched gels), and washed with water for several days to remove unreacted reagents. The gel was then dried in an uncovered Petri dish at $37^{\circ} \mathrm{C}$ for several hours until its diameter shrank to 1-2 $\mathrm{mm}$. To prepare a compressed gel, the dried gel was placed into a Shigemi tube and the protein solution at the desired $\mathrm{pH}$ value was added; the plunger was held in position with Parafilm to give $20 \%$ vertical compression after swelling. Stretched gels were prepared using the funnel apparatus developed by Chou et al. ${ }^{38}$ The dried gel was placed in a funnel with the same ID $(5 \mathrm{~mm})$ as that used to cast the original gel and was rehydrated in the protein solution to its initial size $(5 \mathrm{~mm} \times 25 \mathrm{~mm})$. The swollen gel was then transferred to an open bottom NMR tube (New Era Enterprises; $4.2 \mathrm{~mm}$ ID), which was sealed with a Vespel suscepti- bility matched plug fitted with a Viton O-ring. In both cases, the gels were swollen overnight.

\section{NMR spectroscopy}

NMR experiments were carried out on a Bruker DRX $800 \mathrm{MHz}$ spectrometer with a triple resonance gradient probe head. For native apoMb, dipolar couplings were recorded at $35^{\circ} \mathrm{C}$ using a 2D IPAP-type ${ }^{15} \mathrm{~N}-{ }^{1} \mathrm{H}$ HSQC correlation experiment, ${ }^{62}$ with $2048 \times 512$ complex points and spectral widths of 12019.2 and $2272.7 \mathrm{~Hz}$ for the ${ }^{1} \mathrm{H}$ and ${ }^{15} \mathrm{~N}$ dimensions, respectively. For the acid-unfolded states, ${ }^{15} \mathrm{~N}-{ }^{1} \mathrm{H}$ one-bond dipolar couplings were measured in ${ }^{15} \mathrm{~N},{ }^{13} \mathrm{C}$-labeled protein using a 3D $\mathrm{HNCO}-$ IPAP pulse program ${ }^{37}$ because of poor ${ }^{1} \mathrm{H}$ resonance dispersion. The spectra of apoMb at pH 2.3 and with $8 \mathrm{M}$ urea at $\mathrm{pH} 2.3$ were recorded at $25^{\circ} \mathrm{C}$ and $20^{\circ} \mathrm{C}$ with $2048 \times 96 \times 100$ complex points and the spectral widths of $12820.5 \mathrm{~Hz}, 1404.5 \mathrm{~Hz}$ and $2127.6 \mathrm{~Hz}$ for ${ }^{1} \mathrm{H},{ }^{13} \mathrm{C}$ and ${ }^{15} \mathrm{~N}$ dimensions, respectively. The ${ }^{1} \mathrm{H},{ }^{15} \mathrm{~N}$ and ${ }^{13} \mathrm{C}$ carriers were set at $4.7 \mathrm{ppm}, 118.0 \mathrm{ppm}$ and $173.9 \mathrm{ppm}$, respectively, for all experiments. An external DSS sample in the corresponding buffer solution was used to determine reference frequency for all nuclei. ${ }^{63}$

\section{Data analysis}

NMRPipe software ${ }^{64}$ was used to process all data sets. The spectra were apodized with a $54^{\circ}$ shifted sine square window function in all dimensions. Time domain data in the ${ }^{15} \mathrm{~N}$ and ${ }^{13} \mathrm{C}$ dimensions were linear predicted to increase the number of data points by half and zero-filled either to double the original data size (for the native state) or to 256 points (for unfolded and partially folded states) before Fourier transformation. The NMRview 5 program $^{65}$ was used to confirm the published assignments of backbone chemical shifts for acid-unfolded ${ }^{10}$ and urea-unfolded ${ }^{12}$ apoMb. The PIPP/CAPP suite of programs $^{66}$ was used to measure the dipolar coupling splittings.

\section{Acknowledgements}

We thank Drs Michael Lietzow, Roberto De Guzman, Raphael Stoll and John Chung for stimulating discussions, and Linda Tennant for expert technical help. R.M.B. is a Pew Latin American Fellow. This project was supported by grant DK34909 from the National Institutes of Health.

\section{References}

1. Bryngelson, J. D., Onuchic, J. N., Socci, N. D. \& Wolynes, P. G. (1995). Funnels, pathways, and the energy landscape of protein folding: a synthesis. Proteins: Struct. Funct. Genet. 21, 167-195.

2. Wolynes, P. G., Onuchic, J. N. \& Thirumalai, D. (1995). Navigating the folding routes. Science, 267, $1619-1620$

3. Wright, P. E. \& Dyson, H. J. (1999). Intrinsically unstructured proteins: re-assessing the protein structure-function paradigm. J. Mol. Biol. 293, 321-331. 
4. Dyson, H. J. \& Wright, P. E. (2002). Coupling of folding and binding for unstructured proteins. Curr. Opin. Struct. Biol. 12, 54-60.

5. Tompa, P. (2002). Intrinsically unstructured proteins. Trends Biochem. Sci. 27, 527.

6. Iakoucheva, L. M., Brown, C. J., Lawson, J. D., Obradovic, Z. \& Dunker, A. K. (2002). Intrinsic disorder in cell-signaling and cancer-associated proteins. J. Mol. Biol. 323, 573-584.

7. Kelly, J. W. (2002). Towards an understanding of amyloidogenesis. Nature Struct. Biol. 9, 323-325.

8. Dyson, H. J. \& Wright, P. E. (1996). Insights into protein folding from NMR. Annu. Rev. Phys. Chem. 47, 369-395.

9. Eliezer, D., Yao, J., Dyson, H. J. \& Wright, P. E. (1998). Structural and dynamic characterization of partially folded states of myoglobin and implications for protein folding. Nature Struct. Biol. 5, 148-155.

10. Yao, J., Chung, J., Eliezer, D., Wright, P. E. \& Dyson, H. J. (2001). NMR structural and dynamic characterization of the acid-unfolded state of apomyoglobin provides insights into the early events in protein folding. Biochemistry, 40, 3561-3571.

11. Gulotta, M., Gilmanshin, R., Buscher, T. C., Callender, R. H. \& Dyer, R. B. (2001). Core formation in apomyoglobin: probing the upper reaches of the folding energy landscape. Biochemistry, 40, 5137-5143.

12. Schwarzinger, S., Wright, P. E. \& Dyson, H. J. (2002). Molecular hinges in protein folding: the ureadenatured state of apomyoglobin. Biochemistry, 41, 12681-12686.

13. Tsui, V., Garcia, C., Cavagnero, S., Siuzdak, G., Dyson, H. J. \& Wright, P. E. (1999). Quench-flow experiments combined with mass spectrometry show apomyoglobin folds through an obligatory intermediate. Protein Sci. 8, 45-49.

14. Jamin, M. \& Baldwin, R. L. (1998). Two forms of the $\mathrm{pH} 4$ folding intermediate of apomyoglobin. J. Mol. Biol. 276, 491-504.

15. Jennings, P. A., Dyson, H. J. \& Wright, P. E. (1994). The folding pathway of apomyoglobin. In Statistical Mechanics, Protein-Structure and Protein-Substrate Interactions (Doniach, S., ed.), pp. 7-18, Plenum Press, New York.

16. Eliezer, D., Jennings, P. A., Wright, P. E., Doniach, S., Hodgson, K. O. \& Tsuruta, H. (1995). The radius of gyration of an apomyoglobin folding intermediate. Science, 270, 487-488.

17. Eliezer, D. \& Wright, P. E. (1996). Is apomyoglobin a molten globule? Structural characterization by NMR. J. Mol. Biol. 263, 531-538.

18. Lecomte, J. T., Sukits, S. F., Bhattacharjya, S. \& Falzone, C. J. (1999). Conformational properties of native sperm whale apomyoglobin in solution. Protein Sci. 8, 1484-1491.

19. Griko, Y. V., Privalov, P. L., Venyaminov, S. Y. \& Kutyshenko, V. P. (1988). Thermodynamic study of the apomyoglobin structure. J. Mol. Biol. 202, $127-138$.

20. Griko, Y. V. \& Privalov, P. L. (1994). Thermodynamic puzzle of apomyoglobin unfolding. J. Mol. Biol. 235, $1318-1325$.

21. Dyson, H. J. \& Wright, P. E. (2002). Insights into the structure and dynamics of unfolded proteins from nuclear magnetic resonance. Advan. Protein Chem. 62, 311-340.

22. Gillespie, J. R. \& Shortle, D. (1997). Characterization of long-range structure in the denatured state of staphylococcal nuclease. I. Paramagnetic relaxation enhancement by nitroxide spin labels. J. Mol. Biol. 268, 158-169.

23. Yi, Q., Scalley-Kim, M. L., Alm, E. J. \& Baker, D. (2000). NMR characterization of residual structure in the denatured state of protein L. J. Mol. Biol. 299, 1341-1351.

24. Teilum, K., Kragelund, B. B. \& Poulsen, F. M. (2002). Transient structure formation in unfolded acylcoenzyme A-binding protein observed by sitedirected spin labelling. J. Mol. Biol. 324, 349-357.

25. Lietzow, M. A., Jamin, M., Dyson, H. J. \& Wright, P. E. (2002). Mapping long-range contacts in a highly unfolded protein. J. Mol. Biol. 322, 655-662.

26. Shortle, D. \& Ackerman, M. S. (2001). Persistence of native-like topology in a denatured protein in $8 \mathrm{M}$ urea. Science, 293, 487-489.

27. Bax, A. (2003). Weak alignment offers new NMR opportunities to study protein structure and dynamics. Protein Sci. 12, 1-16.

28. Prestegard, J. H., Al Hashimi, H. M. \& Tolman, J. R. (2000). NMR structures of biomolecules using field oriented media and residual dipolar couplings. Quart. Rev. Biophys. 33, 371-424.

29. Tjandra, N. \& Bax, A. (1997). Direct measurement of distances and angles in biomolecules by NMR in a dilute liquid crystalline medium. Science, 278, $1111-1114$.

30. Hansen, M. R., Mueller, L. \& Pardi, A. (1998). Tunable alignment of macromolecules by filamentous phage yields dipolar coupling interactions. Nature Struct. Biol. 5, 1065-1074.

31. Sass, H. J., Musco, G., Stahl, S. J., Wingfield, P. T. \& Grzesiek, S. (2000). Solution NMR of proteins within polyacrylamide gels: diffusional properties and residual alignment by mechanical stress or embedding of oriented purple membranes. J. Biomol. NMR, 18, 303-309.

32. Tycko, R., Blanco, F. J. \& Ishii, Y. (2000). Alignment of biopolymers in strained gels: a new way to create detectable dipole-dipole couplings in highresolution biomolecular NMR. J. Am. Chem. Soc. 122, 9340-9341.

33. Ackerman, M. S. \& Shortle, D. (2002). Molecular alignment of denatured states of staphylococcal nuclease with strained polyacrylamide gels and surfactant liquid crystalline phases. Biochemistry, 41, 3089-3095.

34. Ackerman, M. S. \& Shortle, D. (2002). Robustness of the long-range structure in denatured staphylococcal nuclease to changes in amino acid sequence. Biochemistry, 41, 13791-13797.

35. Ohnishi, S. \& Shortle, D. (2003). Observation of residual dipolar couplings in short peptides. Proteins: Struct. Funct. Genet. 50, 546-551.

36. Ottiger, M., Delaglio, F. \& Bax, A. (1998). Measurement of $\mathrm{J}$ and dipolar couplings from simplified two-dimensional NMR spectra. J. Magn. Reson. 131, 373-378.

37. Goto, N. K., Skrynnikov, N. R., Dahlquist, F. W. \& Kay, L. E. (2001). What is the average conformation of bacteriophage T4 lysozyme in solution? A domain orientation study using dipolar couplings measured by solution NMR. J. Mol. Biol. 308, 745-764.

38. Chou, J. J., Gaemers, S., Howder, B., Louis, J. M. \& Bax, A. (2001). A simple apparatus for generating stretched polyacrylamide gels, yielding uniform alignment of proteins and detergent micelles. J. Biomol. NMR, 21, 377-382. 
39. Alexandrescu, A. T. \& Kammerer, R. A. (2003). Structure and disorder in the ribonuclease S-peptide probed by NMR residual dipolar couplings. Protein Sci. 12, 2132-2140.

40. Ohnishi, S., Lee, A. L., Edgell, M. H. \& Shortle, D. (2004). Direct demonstration of structural similarity between native and denatured eglin c. Biochemistry, 43, 4064-4070.

41. Schwarzinger, S., Kroon, G. J. A., Foss, T. R., Wright, P. E. \& Dyson, H. J. (2000). Random coil chemical shifts in acidic $8 \mathrm{M}$ urea: implementation of random coil chemical shift data in NMRView. J. Biomol. NMR, 18, 43-48.

42. Schwarzinger, S., Kroon, G. J. A., Foss, T. R., Chung, J., Wright, P. E. \& Dyson, H. J. (2001). Sequence dependent correction of random coil NMR chemical shifts. J. Am. Chem. Soc. 123, 2970-2978.

43. Kuhn, W. (1934). The shape of fibrous molecules in solution. Kolloid Z. 68, 2-15.

44. Haber, C., Ruiz, S. A. \& Wirtz, D. (2000). Shape anisotropy of a single random-walk polymer. Proc. Natl Acad. Sci. USA, 97, 10792-10795.

45. Flory, P. J. (1969). Statistical Mechanics of Chain Molecules, Wiley, New York.

46. Pappu, R. V., Srinivasan, R. \& Rose, G. D. (2000). The Flory isolated-pair hypothesis is not valid for polypeptide chains: implications for protein folding. Proc. Natl Acad. Sci. USA, 97, 12565-12570.

47. Cantor, C. R. \& Schimmel, P. R. (1980). Biophysical Chemistry, W.H. Freeman and Company, New York.

48. Damaschun, G., Damaschun, H., Gast, K., Misselwitz, R., Müller, J. J., Pfeil, W. \& Zirwer, D. (1993). Cold denaturation-induced conformational changes in phosphoglycerate kinase from yeast. Biochemistry, 32, 7739-7746.

49. Schwalbe, H., Fiebig, K. M., Buck, M., Jones, J. A. Grimshaw, S. B., Spencer, A. et al. (1997). Structural and dynamical properties of a denatured protein. Heteronuclear 3D NMR experiments and theoretical simulations of lysozyme in $8 \mathrm{M}$ urea. Biochemistry, 36, 8977-8991.

50. Louhivuori, M., Paakkonen, K., Fredriksson, K., Permi, P., Lounila, J. \& Annila, A. (2003). On the origin of residual dipolar couplings from denatured proteins. J. Am. Chem. Soc. 125, 15647-15650.

51. Dyson, H. J. \& Wright, P. E. (1991). Defining solution conformations of small linear peptides. Annu. Rev. Biophys. Biophys. Chem. 20, 519-538.

52. Eker, F., Griebenow, K., Cao, X., Nafie, L. A. \& Schweitzer-Stenner, R. (2004). Tripeptides with ionizable side chains adopt a perturbed polyproline II structure in water. Biochemistry, 43, 613-621.

53. Zhang, O. \& Forman-Kay, J. D. (1995). Structural characterization of folded and unfolded states of an $\mathrm{SH} 3$ domain in equilibrium in aqueous buffer. Biochemistry, 34, 6784-6794.
54. Meekhof, A. E. \& Freund, S. M. V. (1999). Probing residual structure and backbone dynamics on the milli- to picosecond timescale in a urea-denatured fibronectin type III domain. J. Mol. Biol. 286, 579-592.

55. Frank, M. K., Clore, G. M. \& Gronenborn, A. M. (1995). Structural and dynamic characterization of the urea denatured state of the immunoglobulin binding domain of streptococcal protein $\mathrm{G}$ by multidimensional heteronuclear NMR spectroscopy. Protein Sci. 4, 2605-2615.

56. Shi, Z. S., Woody, R. W. \& Kallenbach, N. R. (2002). Is polyproline II a major backbone conformation in unfolded proteins? Unfolded Proteins, 62, 163-240.

57. Rucker, A. L. \& Creamer, T. P. (2002). Polyproline II helical structure in protein unfolded states: lysine peptides revisited. Protein Sci. 11, 980-985.

58. Reymond, M. T., Merutka, G., Dyson, H. J. \& Wright, P. E. (1997). Folding propensities of peptide fragments of myoglobin. Protein Sci. 6, 706-716.

59. Fieber, W., Kristjansdottir, S. \& Poulsen, F. M. (2004). Short-range, long-range and transition-state interactions in the denatured state of ACBP from residual dipolar couplings. J. Mol. Biol. 339, 1191-1199.

60. Alexandrescu, A. T., Abeygunawardana, C. \& Shortle, D. (1994). Structure and dynamics of a denatured 131-residue fragment of staphylococcal nuclease: a heteronuclear NMR study. Biochemistry, 33, 1063-1072.

61. Edelhoch, H. (1967). Spectroscopic determination of tryptophan and tyrosine in proteins. Biochemistry, 6, 1948-1954.

62. Ishii, Y., Markus, M. A. \& Tycko, R. (2001). Controlling residual dipolar couplings in high-resolution NMR of proteins by strain induced alignment in a gel. J. Biomol. NMR, 21, 141-151.

63. Wishart, D. S., Bigam, C. G., Yao, J., Abildgaard, F., Dyson, H. J., Oldfield, E. et al. (1995). ${ }^{1} \mathrm{H},{ }^{13} \mathrm{C}$ and ${ }^{15} \mathrm{~N}$ chemical shift referencing in biomolecular. NMR. J. Biomol. NMR, 6, 135-140.

64. Delaglio, F., Grzesiek, S., Vuister, G. W., Guang, Z., Pfeifer, J. \& Bax, A. (1995). NMRPipe: a multidimensional spectral processing system based on UNIX pipes. J. Biomol. NMR, 6, 277-293.

65. Johnson, B. A. \& Blevins, R. A. (1994). NMRView: a computer program for the visualization and analysis of NMR data. J. Biomol. NMR, 4, 604-613.

66. Garrett, D. S., Powers, R., Gronenborn, A. M. \& Clore, G. M. (1991). A common sense approach to peak picking in two-,three, and four-dimensional spectra using automatic computer analysis of contour diagrams. J. Magn. Reson. 95, 214-220.

67. Wishart, D. S. \& Sykes, B. D. (1994). Chemical shifts as a tool for structure determination. Methods Enzymol. 239, 363-392.

Edited by M. F. Summers 